\title{
EDUCACIÓN FÍSICA... LA FUERZA DEL DISPOSITIVO BIOPOLÍTICO EN LA EDUCACIÓN DEL CUERPO
}

\author{
Angela Liliana Rocha Bidegain \\ Universida Nacional de La Plata, Argentina.
}

\begin{abstract}
Resumen
Es claro que nuestro punto de partida es el presente. Sin embargo, es preciso recurrir al pasado para comprender ciertos aspectos de esta realidad que nos ocupa, es preciso mostrar que no es "natural" que las cosas sean de este modo y ello no se logra sino revisando la historia, mostrando que nada de inocente hay en el modo en que se interpretan los hechos, que las "cosas" no han sido siempre así y por tanto que podrían ser de otro modo. Se podría decir que en el gran calidoscopio de la teoría, cada parte forma el todo, pero ¿qué todo? Esta es la pregunta que intentaremos responder, y para ello es preciso analizar cómo fue que cada parte se fue ubicando, qué lugar le fue asignado y en todo caso, ¿para qué le fue asignado?
\end{abstract}

Palabras-claves: Educación Física - Biopolítica - Dispositivo - Subjetividad.

\section{Educación Física... la fuerza del dispositivo biopolítico en la educación del cuerpo}

$\mathrm{E}$ s claro que nuestro punto de partida es el presente y que los temas que nos interesan son del orden del aquí y ahora. Sin embargo, es preciso recurrir al pasado para comprender ciertos aspectos de esta realidad que nos ocupa; es preciso mostrar que no es "natural" que las cosas sean de este modo y ello no se logra sino revisando la historia, mostrando que nada de inocente hay en el modo en que se interpretan los hechos, que las "cosas" no han sido siempre así y, por tanto, que podrían ser de otro modo. Este cometido no se logra sin recurrir a la génesis, sin historizar, sin mostrar los nudos de esa trama que se ha ido tejiendo poco a poco para llegar a conformar este tapiz, esta Educación Física que nos tiene entrampados como al perro de Pavolov la campanilla. Se podría decir que en el gran calidoscopio de la teoría, cada parte forma el todo, pero ¿qué todo? Esta es la pregunta que intentaremos responder, y para ello es preciso analizar cómo fue que cada parte se fue ubicando, qué lugar le fue asignado y en todo caso, ¿para qué le fue asignado?

Mucho se ha hablado en Educación Física acerca de las corrientes psicomotriz, físico deportiva y físico-pedagógica. No obstante, nos detendremos aquí en el análisis de aquellos aspectos que tienen de regular estas tres versiones, es decir, en la idea de que existe una "naturaleza humana"; que hay algo tal como "El Hombre" en tanto universal a-histórico, fijo e indiviso, que el cuerpo es equivalente al "organismo", a la carne, por lo tanto también circunscrito al orden de lo natural; que el "medio" am- 
biente que condiciona y modela también aparece descrito en términos físicos, como marco contextual que rodea y enmarca, pero nunca atraviesa.

Esas tres perspectivas, se podría decir, conforman un mismo dispositivo: la Educación Física. Cada corriente cambia el nombre, cambia el modo, pero no cambia el sentido, y entonces me pregunto, cómo se piensa y, por tanto, cómo se investiga el aprendizaje motor, cuál es el efecto que eso tiene en las prácticas, qué supone pensar en una naturaleza que dota de determinadas cualidades a uno y a otros, qué enmascaran las teorías del aprendizaje y del desarrollo y, por consiguiente, las del aprendizaje y del desarrollo motor, cuál es el soporte ideológico de estos modos de pensar, hacer y decir y, por último, cómo se sale este dispositivo.

Ahora bien, antes de analizar en detalle qué implica cada uno de estos puntos, trataremos de definir qué se entiende por dispositivo en el marco de esta tesis.

El término Dispositivo aparece en Foucault en los años '70. Edgardo Castro (2005), en el apartado dedicado al concepto, detalla: 1) El dispositivo es la red de relaciones que se puede establecer entre elementos heterogéneos: discursos, instituciones, arquitectura, reglamentos, leyes, medidas administrativas, enunciados científicos, proposiciones filosóficas, morales, filantrópicas, lo dicho y lo no-dicho; 2) El dispositivo establece la naturaleza del nexo que puede existir entre estos elementos heterogéneos. Por ejemplo, el discurso puede aparecer como programa de una institución, como un elemento que puede justificar u ocultar una práctica, o funcionar como una interpretación a posteriori de esta práctica, o, aún, ofrecerle un campo nuevo de racionalidad; 3) Se trata de una formación que en un momento dado ha tenido por función responder a una urgencia. El dispositivo tiene así una función estratégica, como, por ejemplo, la reabsorción de una masa de población flotante que era excesiva para una economía mercantilista (este imperativo estratégico jugó como la matriz de un dispositivo que se convirtió poco a poco en el control-sujeción de la locura, de la enfermedad mental, de la neurosis); 4) Además de definirse por la estructura de elementos heterogéneos, un dispositivo se define por su génesis. Foucault distingue al respecto dos momentos esenciales: un primer momento del predominio del objetivo estratégico y un segundo momento de la constitución del dispositivo propiamente dicho; 5) El dispositivo, una vez constituido, permanece tal en la medida en que tiene lugar un proceso de sobredeterminación funcional: cada efecto, positivo o negativo, querido o no-querido, entra en resonancia o contradicción con los otros y exige un reajuste.

Si bien al principio el dispositivo designa los operadores materiales del poder, es decir, las técnicas, estrategias y formas de sujeción utilizadas por el poder, luego será ampliado al punto que un dispositivo es

un conjunto decididamente heterogéneo que engloba discursos, instituciones, organizaciones arquitectónicas, decisiones reglamentarias, leyes, medidas administrativas, enunciados científicos, proposiciones filosóficas, morales, filantrópicas. En suma lo dicho y no-dicho [...]. El dispositivo es la red que se puede establecer entre esos elementos. (REVÈL, 2005)

Giorgio Agamben (2005, p. 6) va más allá:

llamaré dispositivos a cualquier cosa que tenga de algún modo la capacidad de capturar, orientar, determinar, interceptar, modelar, controlar y asegurar los gestos, las conductas, las opiniones y los discursos de los seres vivientes. No solamente, por lo tanto, las prisiones, los manico- 
mios, el panóptico, las escuelas, la confesión, las fábricas, las disciplinas, las medidas jurídicas, etc., cuya conexión con el poder es en cierto sentido evidente, sino también la lapicera, la escritura, la literatura, la filosofía, la agricultura, el cigarrillo, la navegación, las computadoras, los celulares y -por qué no- el lenguaje mismo, que es quizás el más antiguo de los dispositivos, en el que millares y millares de años un primate -probablemente sin darse cuenta- tuvo la inconsciencia de dejarse capturar.

Agamben generaliza la noción de dispositivo hasta hacerla coincidir con cualquier mecanismo que sea capaz de gobernar la vida.

Si todo es dispositivo, si el lenguaje es "el dispositivo de los dispositivos", consideraremos de aquí en más a la Educación Física como un dispositivo de la educación del cuerpo. Agamben propone una clasificación general de los seres en dos clases: los seres vivientes y los dispositivos. La función de los dispositivos es justamente capturar lo viviente, dando lugar, a través de esta captura, a los procesos de subjetivación y de desobjetivación (CASTRO y AGAMBEN, 2008). Ahora bien, entre los seres vivientes y el dispositivo están los sujetos. Agamben llama sujeto a lo que resulta de esa relación del cuerpo a cuerpo entre lo viviente y los aparatos. Por lo tanto, él "no es una sustancia. Es una forma, y esta forma no es sobre todo ni siempre idéntica a sí misma" (Castro, 2004). Como sostienen Caruso y Dussel (1997), "el sujeto no está ahí dado, sino que se construye. No hay condiciones predeterminadas que determinen que uno sea lo que es por el hecho de existir". Entonces, los sujetos se constituyen como tales en una red de significaciones, a partir de "los otros", con "los otros" en y por el "Otro", que determina la posición del sujeto y otorga sentido a sus acciones. Para decirlo con Lacán, "El inconsciente es el discurso del “Otro”, y es ese discurso el que instaura en el sujeto ese lugar Otro que es el inconsciente, [...] es sujeto el que es instaurado en ese lugar ya que habla a partir de allî" (D'ANGELO; CARABAJAL; MARCHILLI, 2000, p. 38). Por tanto, la Educación Física como dispositivo de lo corporal es generadora de subjetividad.

Entonces, si antes decíamos que hay múltiples dispositivos, vemos que un mismo sujeto puede "ser el lugar de múltiples procesos de subjetivación", puede estar atrapado al teléfono celular y a la estética que la sala de musculación le propone/impone. Retomemos entonces el análisis del Dispositivo Educación Física.

Michel Foucault nos advierte que desde la segunda mitad del siglo XIX el poder tiende a transformarse con el objeto de gobernar a los individuos por medio de un cierto número de procedimientos disciplinares, y a través del proceso de medicalización de las sociedades se los convierte en "población”, ejerciendo una política y una gestión de la vida. Así, por medio de los poderes locales, el estado se ocupará de la gestión de la salud, de la higiene, de la alimentación, de la sexualidad, de la natalidad, etc. De este modo, el saber médico y en especial de la fisiología y la psiquiatría se convierten en el parámetro de todo saber legítimo, que trascendiendo al enfermo y a las enfermedades pasan a ocuparse de otros campos de saber. Se pone en marcha una tecnología reguladora de la vida, cuyo objetivo no sería tanto regular los cuerpos individuales cuanto el cuerpo social, las poblaciones. Estas tecnologías, junto con las tecnologías disciplinarias, individualizantes e individualizadoras, se centran en los cuerpos y en los individuos, y ambas ponen en marcha técnicas de racionalización y economía, tecnologías de un poder poco visible, microfísica y capilar, actuando en la formación de nuevos saberes e instituciones destinados a jerarquizar, clasificar, vigilar y adiestrar 
los cuerpos (este es el análisis más frecuentemente realizado dentro de la Educación Física), pero, y por sobre todo, saberes e instituciones destinados a la gestión global de la vida, entre cuyos exponentes figura la higiene pública, la estadística, etc.

Es a partir de este fenómeno de medicalización de la sociedad que la preocupación estará puesta por una parte en definir y diferenciar lo científico de lo no científico, lo racional de lo irracional, y lo normal de lo patológico o anormal. Es en este umbral biológico de la modernidad que la política comienza a preocuparse por establecer parámetros para cada edad, y aquel que no responda a los parámetros establecidos será clasificado como anormal o desviado. Sin embargo, el discurso de la Educación Física, al igual que todas las disciplinas nacidas a la sombra de la biopolítica, no es un discurso ingenuo, sino todo lo contrario, es un discurso que legitima y hace posible la circulación del proyecto de liberalismo burgués (REVĖL, 2005). Dice Judith Revèl (2005) a respecto del análisis de Foucault:

Para que un cierto liberalismo burgués haya sido posible a nivel de las instituciones, fue preciso, en el nivel de los micro-poderes, un investimento mucho más fuerte de los individuos, fue preciso organizar el escudriñamiento de los cuerpos y de los comportamientos.

En este caso la Educación Física, al reproducir modelos y métodos de investigación, ha apuntado a reducir al sujeto humano a la suma de sus comportamientos intentando evaluarlos según procedimientos llamados 'científicos', que son inadecuados a sus objetos, de este modo "invocando razones biológicas, neuronales o cerebrales para explicar supuestas diferencias innatas entre los sexos y las razas, se reinventan discriminaciones que se creían abolidas"(ROUDINESCO, 2007).

La Educación Física en sus tres versiones o corrientes, ha confundido al cuerpo con el organismo. De hecho el concepto de física tiene su raíz etimológica en Physis y remite a la naturaleza, por tanto el cuerpo ha sido, y es, el conjunto de huesos, músculos, articulaciones y un sistema nervioso que organiza por sí mismo nuestras percepciones, pensamientos, emociones y sentimientos. En sus tres versiones, todo su cuerpo teórico (y sus prácticas) han replegado el bios sobre la zoe, y es en ese reduccionismo de la vida política a la vida puramente animal, en la reducción de un estilo o forma de vida a los procesos vitales de la vida común, es decir, de la vida en comunidad a la vida biológica que la educación del cuerpo queda atrapada en el reduccionismo biológico que establece una relación contingente con nuestro cuerpo, que mantiene la acción humana dentro de los límites de determinadas posibilidades anatómicas y fisiológicas, o incluso, al bagaje genético del sujeto. En la medida que considera al movimiento como natural, y por tanto al deporte, el juego y la gimnasia como naturales, en tanto se ha hundido en el test y el peritaje para clasificar y seleccionar a los individuos, no ha hecho más que intentar explicar por una vía muerta los fenómenos de los que se ocupa, con la sola pretensión de explicar y predecir para luego prescribir. Pero, si los rasgos somáticos como los psicológicos están predeterminados desde el nacimiento conforme a una vinculación biológica que ni la voluntad individual ni la educación pueden quebrantar, las virtudes y los signos se convierten en destino ineluctable: nadie puede romper la cadena que lo ata inexorablemente a su propio pasado, haciendo imposible elegir la dirección de la vida. 
Revisar las prácticas de la Educación Física y negar la existencia de algo tal como el hombre, la conciencia y la naturaleza humana nos obliga a intentar comprender cómo y porqué surgen determinadas teorías y supuestos, cómo, porqué y para qué penetran en nuestras prácticas.

Además, las prácticas nos reclaman salir de esta Educación Física, de este dispositivo que nos tiene atrapados en la esfera de lo natural, de la vida puramente animal, y la salida, la forma de romper el circuito receptor-desinhibidor no es interrumpir la práctica, ni hacer desaparecer la Educación Física, sino generar, construir prácticas distintas. Siguiendo a Agamben (2005), la estrategia no es destruir los dispositivos, sino construir un nuevo dispositivo que de lugar a una subjetividad distinta, que de lugar a un nuevo proceso de subjetivación.

Entonces frente al corsé que nos refriega en las narices la pura retórica, empieza a vislumbrarse una salida, empiezan a aparecer pequeñas muestras de que otra educación es posible, de que se pueden formar maestros del cuerpo distintos a los que fuimos y nos mostraron como modelo; que en la medida en que se incluye lo político la investigación en el campo crece y si la Educación Física empieza a tener voz y no se apropia de un discurso ajeno, las prácticas también empiezan a cambiar; que el saber no es propiedad de unos pocos y que nuestros alumnos también saben (algo distinto, pero saben), que los niños son algo más que esa categoría universal y a la vez vacía; que no tiene caso seguir pensando qué teoría del aprendizaje explica con mayor detalle el mecanismo por el cuál un alumno aprende, porque en verdad si quiere aprende y sino no, nada lo puede garantizar, ya que todas las teorías del aprendizaje han mostrado tener una validez relativa, es decir, alguien puede aprender por estímulo-respuesta, por condicionamiento operante, por ensayo y error o por sus propios medios, sin la mediación del profesor, sino de un compañero, pero también ese alumno puede decidir no aprender nada de lo que se le quiere enseñar. Entonces, el problema no se presenta en desentramar los mecanismos por los cuales se aprende, sino en empezar a pensar estrategias diferentes para la enseñanza. Esto nos permitirá dejar de pensar en alumnos (sin luz) a los que hay que alumbrar y docentes (dóciles) que solo trasmiten conocimientos ${ }^{1}$.

En síntesis, hay una tarea por delante: "Profanar lo improfanable", devolver a la Educación Física (más bien incluir porque nunca lo ha sido) a la esfera de lo político. El comienzo, creemos, es construir su propia teoría "desde" las prácticas.

\section{Physical education... The strength of the biopolitical device in the education of the body}

Abstract

It is clear that our starting point is the present, but one needs to reach for the past in order to understand certain aspects of this current reality. It is important to show that it is not natural that things are the way

1 Esta expresión implica a la vez un cambio más profundo en la medida en que "el conocimiento supone la racionalización, identificación y clasificación de objetos juzgados cognoscibles independientemente del sujeto que los aprende, mientras que el saber designa lo contrario, un proceso por el cual el sujeto de conocimiento en vez de ser fijo, sufre modificaciones durante el trabajo que efectúa en la actividad de conocer" (REVÈL, 2005). 
they are now and the only way to achieve this is by revisting history and showing that there is nothing naive about the way facts are interpreted and that things have not always been the way they are and that they could be different. Can we then say that in the great theoretical kaleidoscope, each part makes the whole, but what whole is it? This is the question we will try to answer and, to achieve this, it is of the outmost importance to analyze how each part was placed, which place was designated and what was it designated for? Keywords: Physical Education - Biopolitics - Device - Subjectivity.

\section{Educação física... A força do dispositivo biopolítico na educação do corpo}

\section{Resumo}

É claro que o nosso ponto de partida é o presente. No entanto, é preciso utilizar o passado para compreender certos aspectos da realidade em que vivemos, é necessário mostrar que não é "natural" que as coisas sejam assim, e isso só é possível revisando a história, mostrando que não há nada de inocente na maneira de interpretar os fatos, que as "coisas" nem sempre foram assim e, portanto, que elas poderiam ser de outro jeito. Seria possível dizer que, no grande caleidoscópio da teoria, cada parte forma o todo, mas qual todo? Essa é a questão que tentaremos responder e, para isso, é indispensável analisar como cada parte foi sendo direcionada, qual lugar lhe foi designado e, em todo caso, para que the foi atribuído.

Palavras-chave: Educação Física - Biopolítica - Dispositivo - Subjetividade.

\section{Referencias}

AGAMBEN, G. ¿̨Qué es un dispositivo? Conferencia pronunciada en la Universidad Nacional de La Plata, 2005. Disponible en: http://caosmosin.acracia.net/?p=700.

CASTRO, E. El vocabulario de Michel Foucault. Un recorrido por sus temas, conceptos y autores. Buenos Aires: Universidad Nacional de Quilmes, 2004.

CASTRO, E. y AGAMBEN, G. Una arqueología de la potencia. Buenos Aires: Jorge Baudino ediciones/UNSAM Edita, 2008.

CARUSO, M. y DUSSEL, L. "Yo, tú, él: ¿̨quién es el sujeto?". De Sarmiento a los Simpsons. Cinco conceptos para pensar la educación contemporánea. Buenos Aires: Kapeluz, 1997.

D'ANGELO, R.; CARABAJAL, E.; MARCHILLI, A. Una introducción a Lacan. Buenos Aires: Lugar editorial, 2000.

FOUCAULT, M. Nacimiento de la biopolitica. Curso en el Collage de France (1978-1979). Buenos Aires: Fondo de Cultura Económica, 2007.

REVÈL, J. Foucault. Conceitos esenciais. São Carlos: Claraluz editora, 2005.

Recebido em: 02 de abril de 2009

Revisado em: 05 de maio de 2009

Aprovado em: 10 de julho de 2009

\section{Endereço para correspondência}

lilirocha7@gmail.com

Angela Liliana Rocha Bidegain 
Facultad de Humanidades y Ciencias de la Educación Universidad Nacional de La Plata

Calle 48 entre 6 y 7 - C.P 1900 La Plata - Argentina 